\title{
Estimation of Manning's Roughness Coefficient Through Calibration Using HEC-RAS Model: A Case Study of Rohri Canal, Pakistan
}

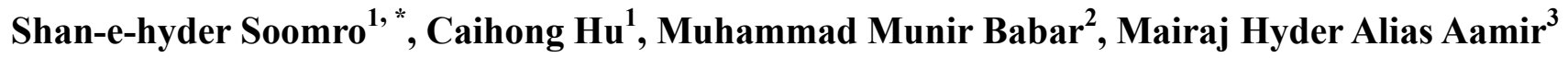 \\ ${ }^{1}$ School of Water Conservancy Science \& Engineering, Zhengzhou University, Zhengzhou, China \\ ${ }^{2}$ U.S.-Pakistan Center for Advanced Studies in Water, Mehran University of Engineering and Technology Jamshoro, Sindh, Pakistan \\ ${ }^{3}$ School of Civil, Mining, and Environment, University of Wollongong, Northfields Ave Wollongong, Australia \\ Email address: \\ shanhydersoomro110@hotmail.com (Shan-e-hyder S.), hucaihong@zzu.edu.cn (Caihong Hu), \\ mmunirbabar.uspcasw@faculty.muet.edu.pk (Muhammad M. B.), mhaas254@uowmail.edu.au (Mairaj H. A. A.) \\ ${ }^{*}$ Corresponding author
}

\section{To cite this article:}

Shan-e-hyder Soomro, Caihong Hu, Muhammad Munir Babar, Mairaj Hyder Alias Aamir. Estimation of Manning’s Roughness Coefficient Through Calibration Using HEC-RAS Model: A Case Study of Rohri Canal, Pakistan. American Journal of Civil Engineering.

Vol. 9, No. 1, 2021, pp. 1-10. doi: 10.11648/j.ajce.20210901.11

Received: October 17, 2020; Accepted: January 14, 2021; Published: January 22, 2021

\begin{abstract}
In understanding the hydraulic characteristics of river system flow, the hydraulic simulation models are essential tools. The suitable value of Manning's roughness coefficient " $n$ " is chosen through method of calibration; i.e., the value which reproduces observed data to an acceptable accuracy. In the present study, the unsteady flow model HEC-RAS is applied to Rohri Canal (upstream Rohri) to estimate value of manning's coefficient through the procedure. Through a series of systematic. Studies to identify the $\mathrm{n}$ values in a hypothetical open channel and a natural stream stretch, several identification procedures based on unconstrained and constrained minimizations are analyzed. However, the decision on what value to adopt is a complex task, especially when dealing with natural water courses due to the various factors that affect this coefficient ' $n$ '. The data was collected in the period of January (2010) to December (2011), and divided equally into two sets. The first set is for calibration purpose, estimation of (n) and the second set for the verification process of testing the model with actual data to establish its predictability accuracy. Graphical and statistical approaches were used for model calibration and verification. Results show that the manning's roughness coefficient " $n$ " for Rohri Canal which shows good agreement between observed and computed hydrograph is 0.042 .
\end{abstract}

Keywords: Manning's Roughness Coefficient, Calibration, Validation, Hydrograph, HEC-RAS

\section{Introduction}

Pakistan has largest unified system of irrigation; it is called as Indus basin Irrigation system (IBIS). No one can overlook its strategic and usual importance. Chashma, Mangla, and Tarbela are its three major reservoirs, consists of 18 barrages, 12 link canals, 45 irrigation canals and more than 107,000 water courses. The length of main canal system is expected about 585000 Kilometer. Indus has most unique catchment area in the sense that it contains seven of the world's highest peaks after Mount Everest and seven glaciers situated in the Indus catchment are among the largest in the world, namely, Siachin, Hispar, Biafo, Baltura, Baltoro, Barpu and Hopper [1].
Pakistan's economy depends upon agriculture which is highly dependent on irrigation which accounts for its $90 \%$ crop production (FAO). Increasing population rate, urbanization growth and adverse climate change has caused severe water crises [2]. Pakistan is considered as being close to water scarcity level with per capita availability of 1017 cubic meters. The World Resources Institute declared that, Pakistan will face a high level of water stress in 2020 and in 2030 the ranking will get worse further to extremely high level, thus Pakistan will be in the list of top 33 countries under extreme water crisis [3]. In spite of having an established irrigation system, huge quantity of water is lost in the water transportation, system causing water logging and 
salinity issues in our agriculture [4]. These losses accounts for $15 \%$ in main water canals, $8 \%$ in water distributaries, and approximately $30 \%$ in watercourses. So, the proper design and maintenance of watercourses will surely reduce these losses and would save water to use it more efficiently [5].

\section{Background of Study}

In an open channel computation of flow needs evaluation of the channel's resistance to flow, which is typically characterized by a roughness parameter, such as Manning's " $n$ " [6]. Estimation of Manning's roughness coefficient " $n$ " is a significant tool to simulate flow of open channels. The roughness coefficient used in the study of streams hydraulic behavior modeling [7]. The actual behavior of stream can stimulate with numerical modelling. Hydraulic modelling has big concern with respect to water resources management, strategic planning and crises management like in order to prepare flooding maps, Peak discharge, low water levels, and hydraulic structures projects like dam or Reliable information on different situation is only provided by well calibrated hydraulic model ridges [8-9].

The Manning's equation as an empirical equation applies on uniform flow in open channels, is a function of the channel velocity, flow area and channel slope. According to Ding and Wang in 2004 that, the coefficient of roughness, an experimental parameter, adds up so many components including resistance caused by surface friction, structural resistance, wave resistance and unsteady flow resistance [10]. This coefficient cannot be measured directly and there is no exact process for its selection, values are often assigned from tables defining well established empirical approximations of common land classifications [11].

In the process of calibration of model, trial and error method is used to estimate the coefficient of roughness from the comparative study of field data and computational figure of stage and discharge [12]. According to Chow in 1959 that, it is almost impossible to evaluate the coefficient of roughness in field. Simulation of unsteady flow may require adjustment of the frictional slope. So most of the works uses Manning's equation of steady flow, which is acceptable [13]. It was reported by Fenton in 2002 that the value of ' $n$ ' for natural irrigation channels, typically is 0.025 , however it ranges in between from 0.022 to 0.033 for earthen channels. There is no specific method of selecting this value, while using the equation [14]. The coefficient of roughness ' $n$ ' value is depends upon factors, like roughness, irregularities, curvature and increase in hydraulic radius of channel [15].

The coefficient of roughness is referred as friction between the flowing water and channel structure. Additionally, if the channel bed and channel banks found to be flat, steady and slope of bottom is regular, then it would be constant at all the stages [16]. Usually, it is very uncommon for engineers to think or assume the same value of ' $n$ ' at all stages. The selection of a suitable coefficient can be challenging, involving practical experience, individual and local judgements, which could result in getting different values in the analysis of the same channel [17]. Value of roughness coefficient is influenced by many factors. It depends upon many factors, like roughness, irregularities, curvature and increase in hydraulic radius of channel [18]. In the literature we found software that calculates the roughness coefficient from the Manning equation. US army crops engineers developed HEC-RAS model [19]. This software allows unsteady flow and one dimensional steady flow stimulation in gradually and rapidly varied flow analysis. In simple words this model is useful in studying hydraulic characteristics of a river [20-23].

In present research Estimation Manning's coefficient of roughness ' $n$ ' via HEC-RAS model for Rohri Canal, Sindh Pakistan. Calibrate the model for said channel reaches for observed data of year 2010. The validation of the model for the said channel reaches for observed data of year 2011. The selected Rohri Canal being one of the largest irrigation canals in the world, the length of the canal is $1038 \mathrm{Rds}$. It was originally designed for 10887 cusecs discharge to irrigate gross commanded area of 2.83 million acres at $81 \%$ intensity i.e. $27 \%$ for the kharif and $54 \%$ for Rabi (Figure 1 ).

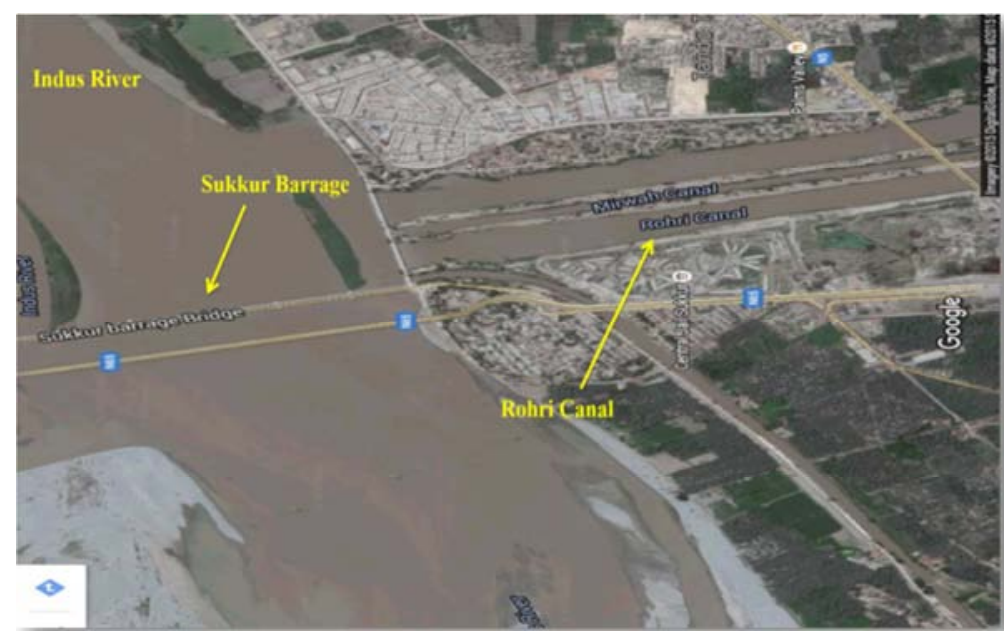

Source: Google Earth

Figure 1. Aerial view of the Study Area. 


\section{Materials and Methodology}

\subsection{Manning's Roughness Coefficient}

According to Ding and Wang in 2004 that, it is almost impossible to directly determine the coefficient of roughness in natural river water flow, including unsteady channel network flow. It was reported by Chow in 1959 that, it is impossible to evaluate the coefficient of roughness in field.

\subsection{Development of HEC-RAS Software Model}

The Hydrologic Engineering Center River Analysis system (HEC-RAS) model was developed by the U.S. Army Corps of Engineers. It is used at a professional level, allowing us to do simulation of one dimensional steady flow and unsteady flow. It is also used to design and develop one dimensional calculations of full network hydraulics of artificial and natural channels. Following figure is showing the main menu of HEC-RAS software tool.

\subsection{Unsteady Flow HEC-RAS Model of Rohri Canal}

This research is done on the 7 reaches of Rohri Canal (Figure 3). All reaches are drawn from upstream to downstream in flow direction using the software.

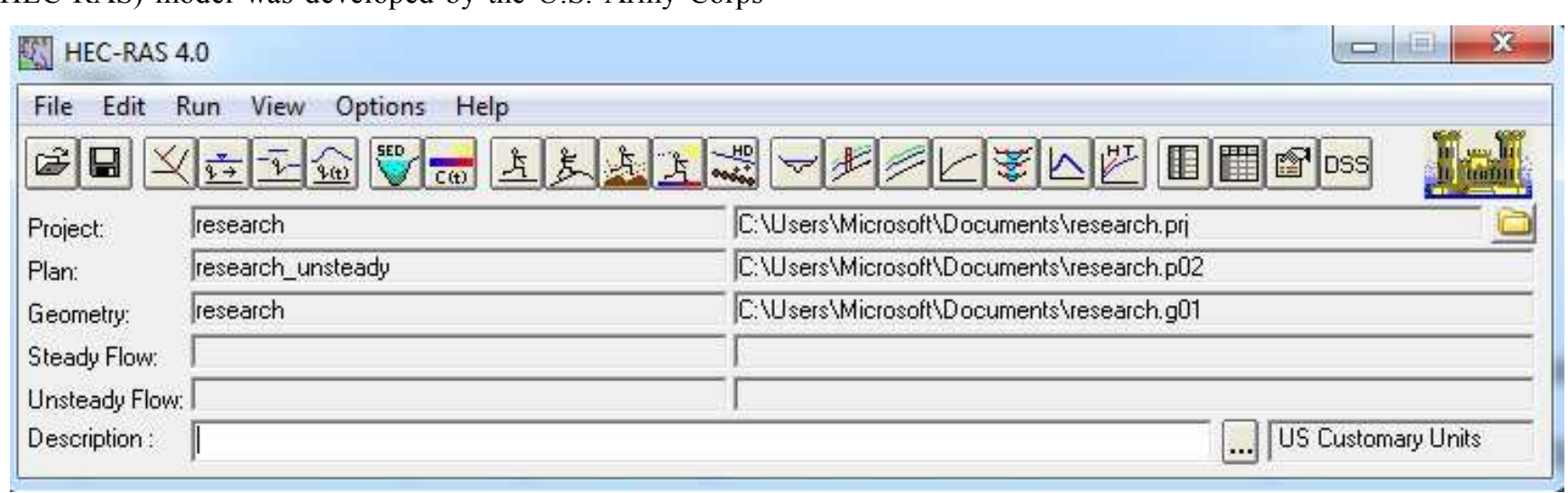

Figure 2. Main menu of HEC-RAS.

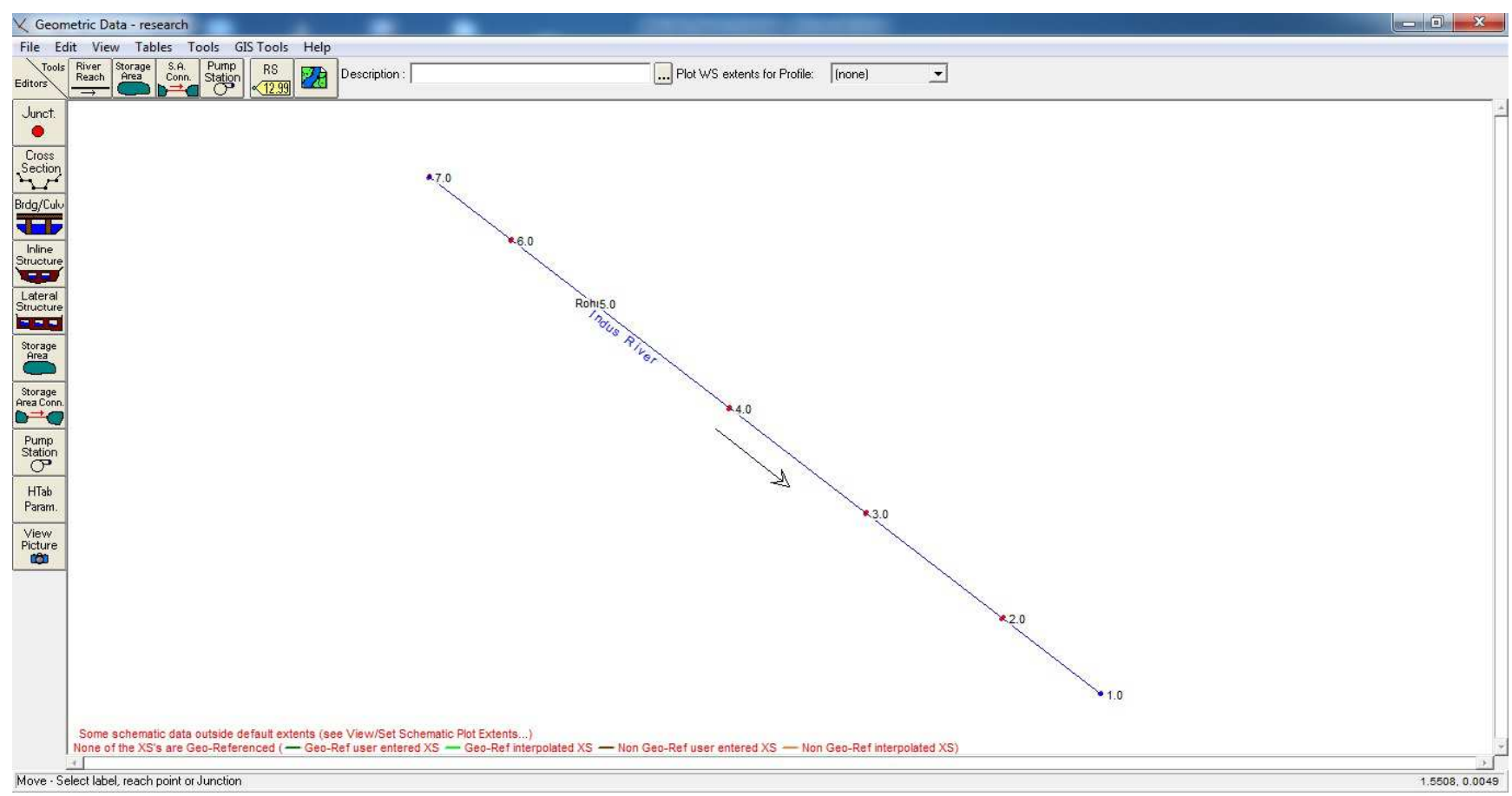

Figure 3. 7 reaches of Rohri Canal-Schematic view.

After that, the stage is to put in necessary geometric data required to connect the information for the whole system. The geometric data includes the following parameters:

(1) Cross sectional data highlighting the boundary of the channel

(2) River reach and river station identifiers; like station and elevation points

The geometric presentation by this software HEC-RAS is shown in the Figure 4. 


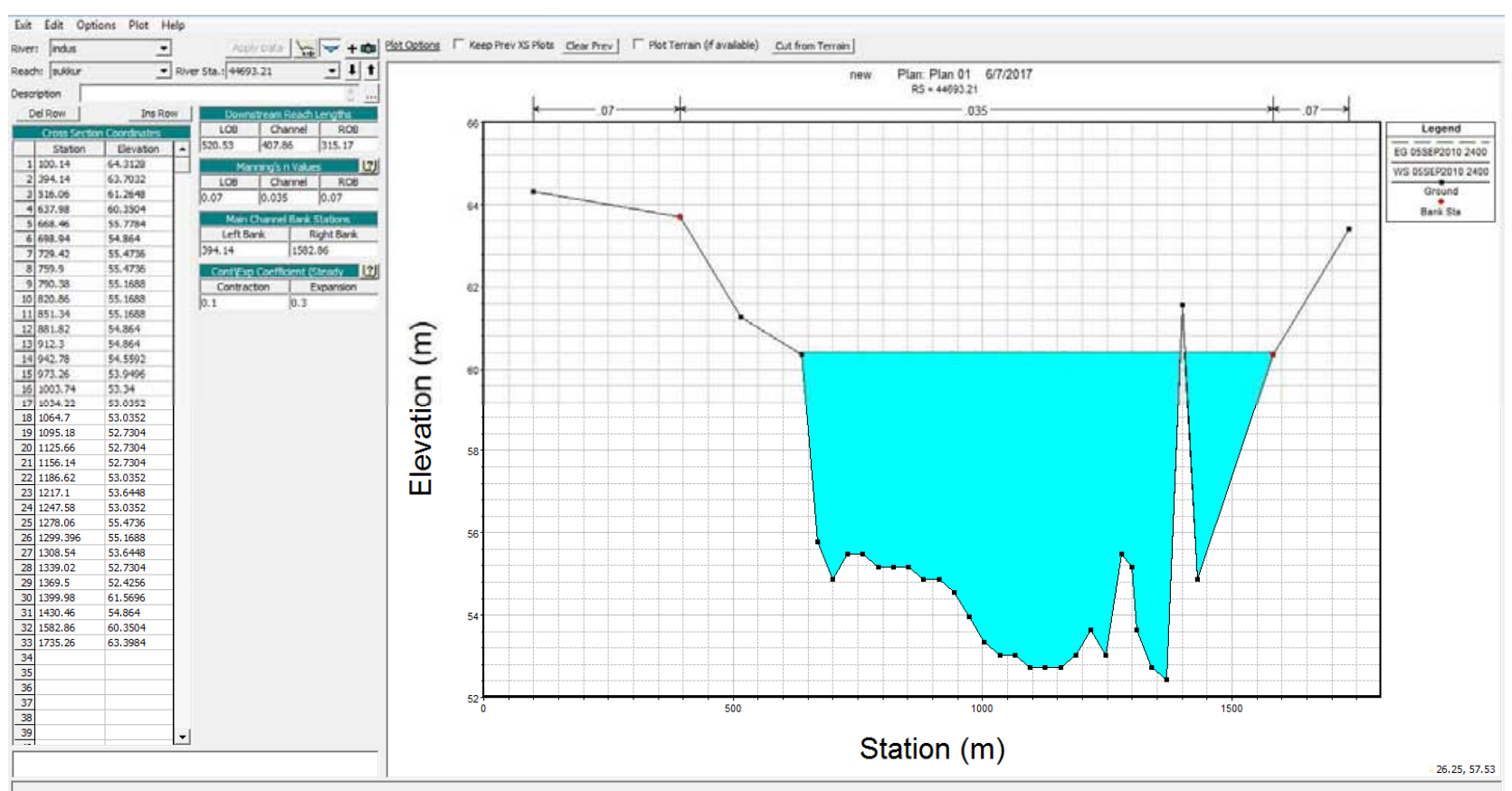

Figure 4. Cross-sectional Data Editor of HEC-RAS model.

\subsection{Data Collection}

For the present research purpose primary data from Sukkur Barrage from RD - 0 to RD - 118 for the years 2010 and 2011 was collected. Calibration of HEC-RAS model would be done for the year 2010 and on the data of year 2011 verification would be done to check the accuracy of calibrated model. For the development of HEC-RAS model geometric data, cross- sectional data, steady flow data, and unsteady flow data was collected from study area. Geometric data consists of connecting river systems, cross-section data, reach lengths, energy loss coefficients (losses due to friction, expansion, and contraction), and stream junction information. The crosssectional coordinates along with reach lengths, manning's value, and coefficients of expansion and contraction (Figure 3 ).

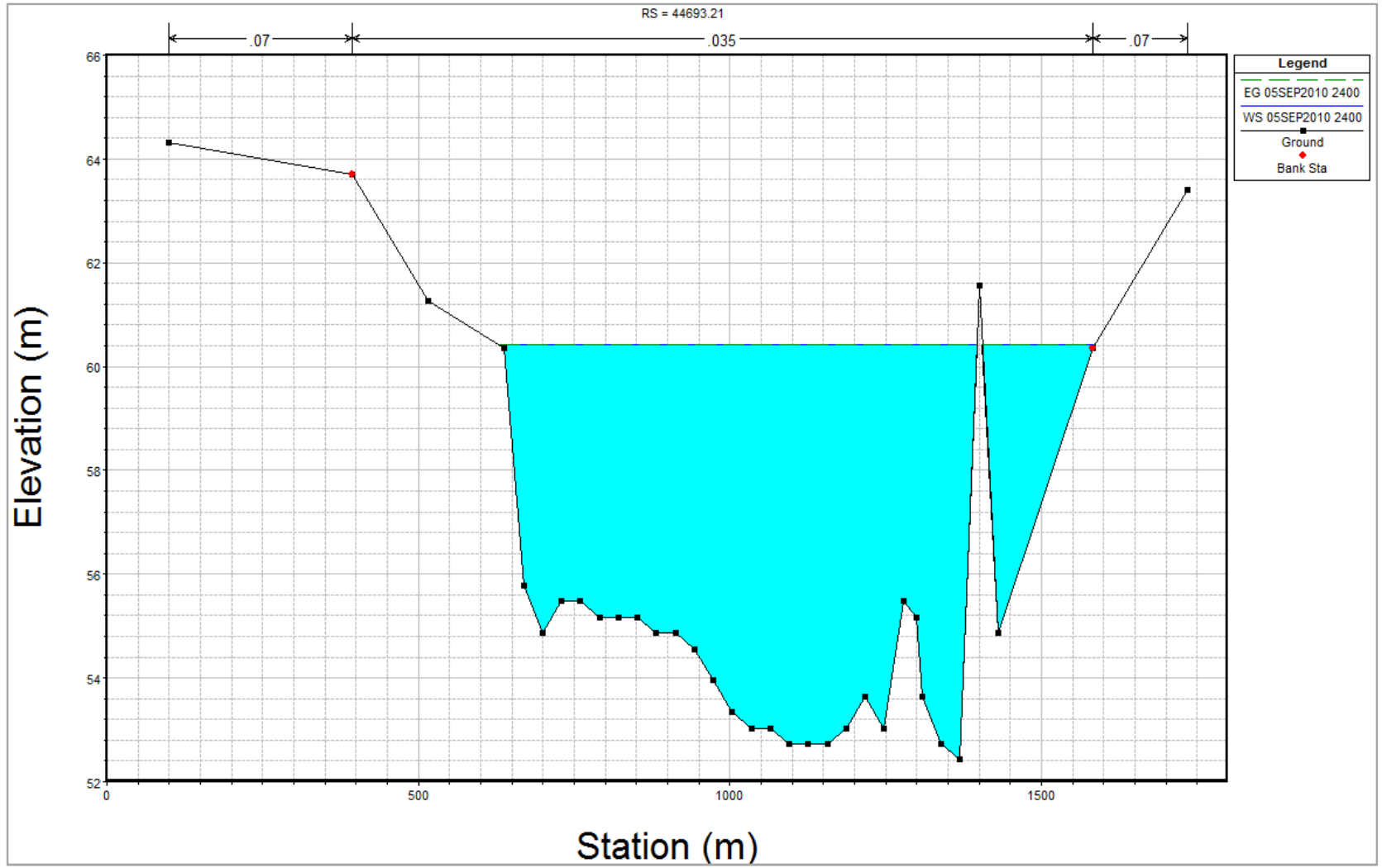

Figure 5. Cross sectional view (Source: Field Survey). 


\section{Results and Discussion}

\subsection{HEC-RAS Model Calibration for the Rohri Canal}

The data considered for Calibration purpose of the analysis is for the period from January, 2010 to December, 2010. However, for the verification of model created in HEC-RAS software, the data considered is for the period of January to December in 2011. In the first phase of the data, the manning's roughness coefficient is estimated, however, in the later part of the data, verification is done. In this case, the boundary condition at the upstream is set be the observed discharge hydrograph for the unsteady flow (Figure 5) at station-1. The discharge is observed at monthly intervals for this case. Furthermore, if we talk about the boundary condition at the downstream, then the stage hydrograph is set as the boundary condition at station-7 (Figure 6).

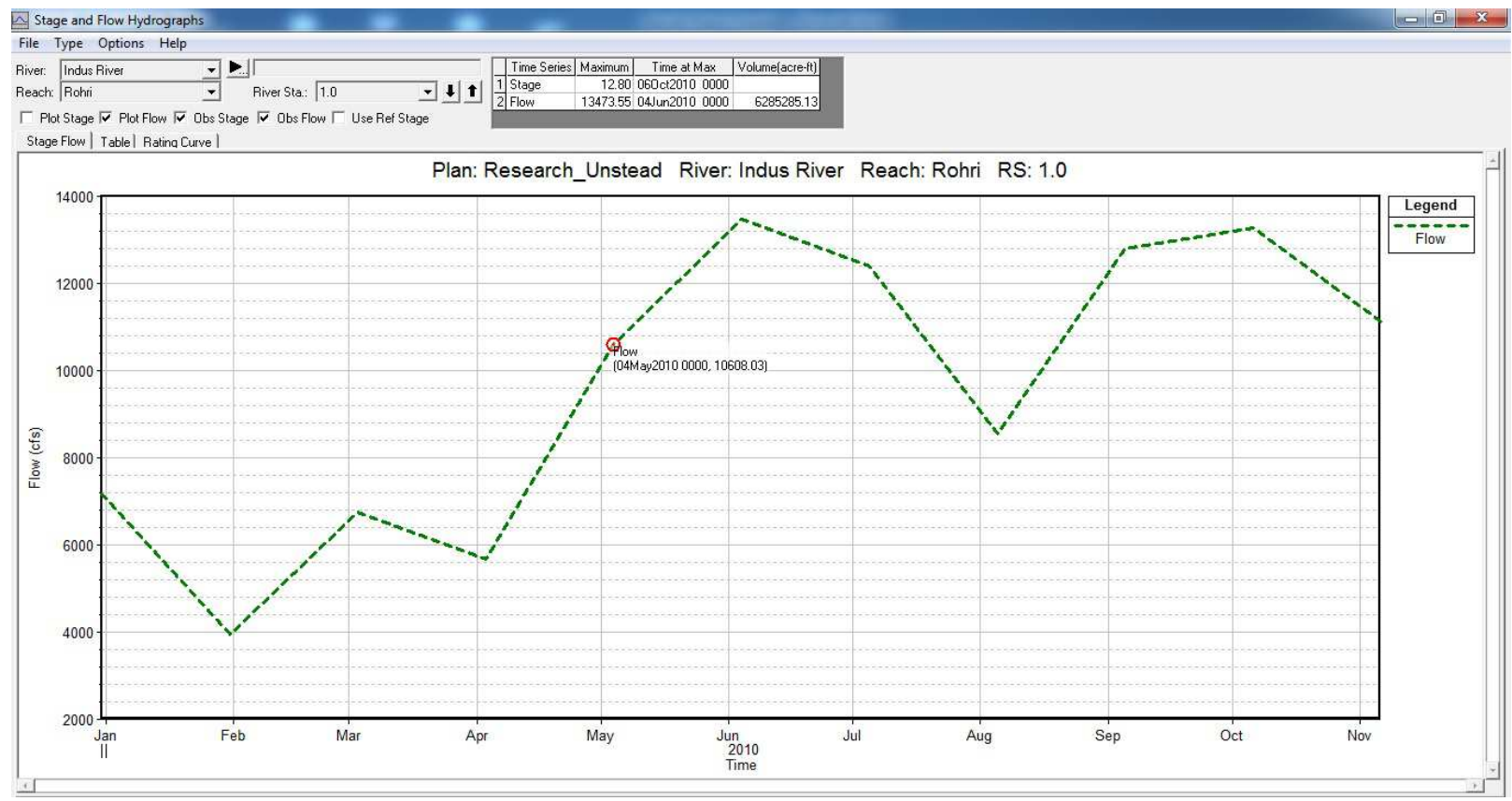

Figure 6. Discharge Hydrograph of Station-1 (Observed Data).

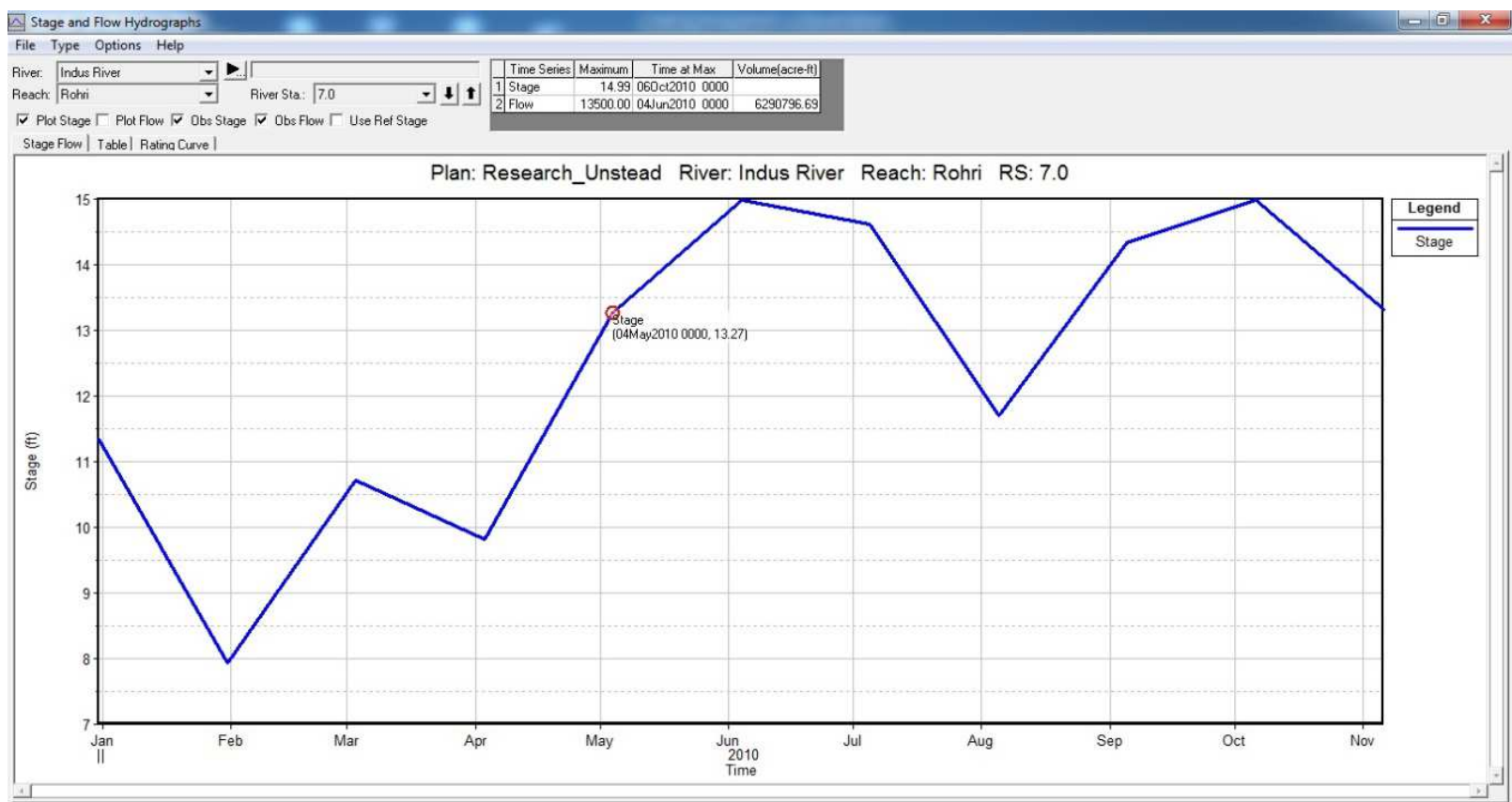

Figure 7. Stage Hydrograph of Station-7 (Observed Data).

In the present research, the initial conditions set are the discharge and stage along the Rohri Canal determined at the initial time using the steady flow computations using the software, considering decrease in discharge in Rohri Canal (because of the diversions) (Figure 7; Figure 8). 


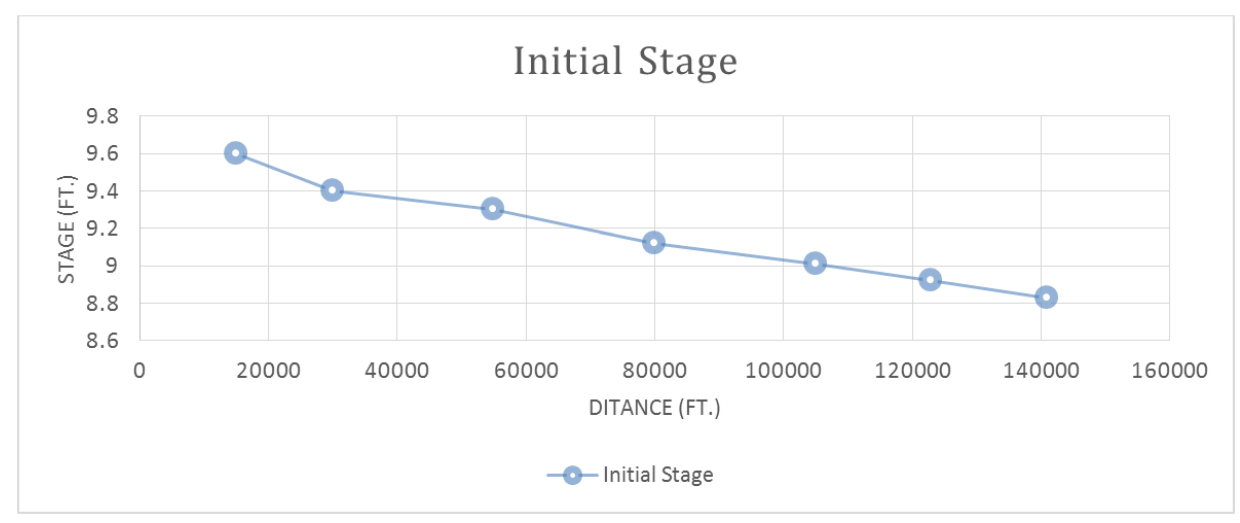

Figure 8. Initial Stage.

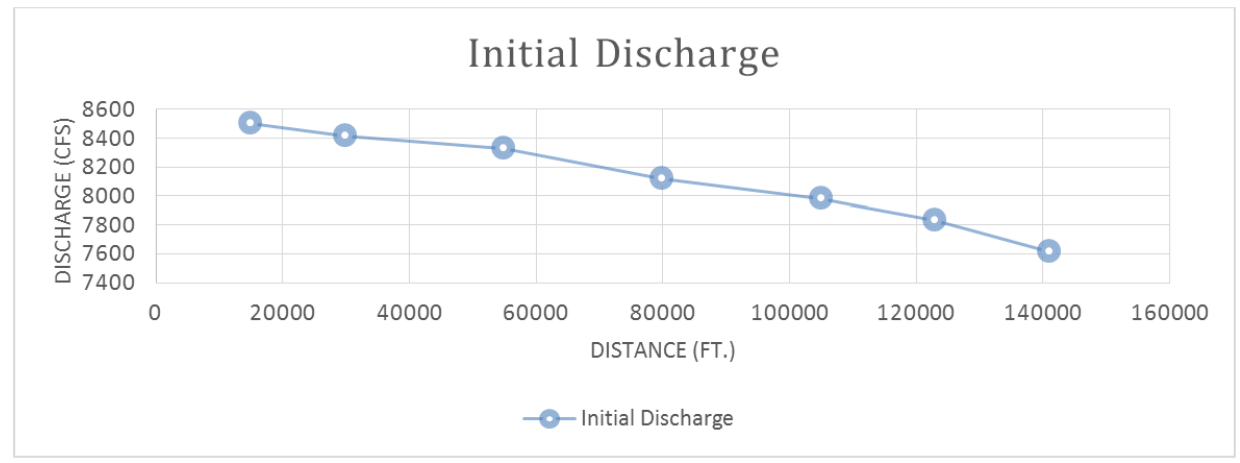

Figure 9. Initial Discharge.

For this simulation model made of unsteady flow using the software, the value assumed of roughness coefficient ' $\mathrm{n}$ ' for the Rohri Canal falls in the range of 0.040 to 0.045 . To obtain the results, we further need the values of ' $\theta$ ' and ' $\Delta \mathrm{t}$ '. The values of these two parameters are set to be 0.095 and 1 month respectively. As ' $\Delta \mathrm{t}$ ' is representing the time here. Using these two values, the stage and observed hydrographs at station- 1 and station-7 of this research are compared and evaluated (Figure 9; Figure 10).

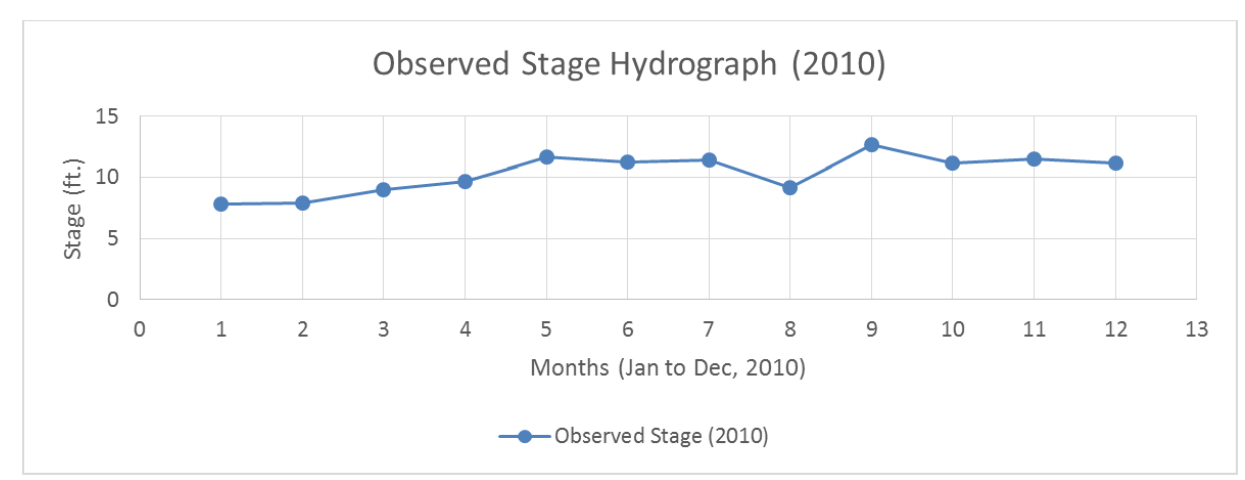

Figure 10. Stage Hydrograph at Station-1 (Observed Data).

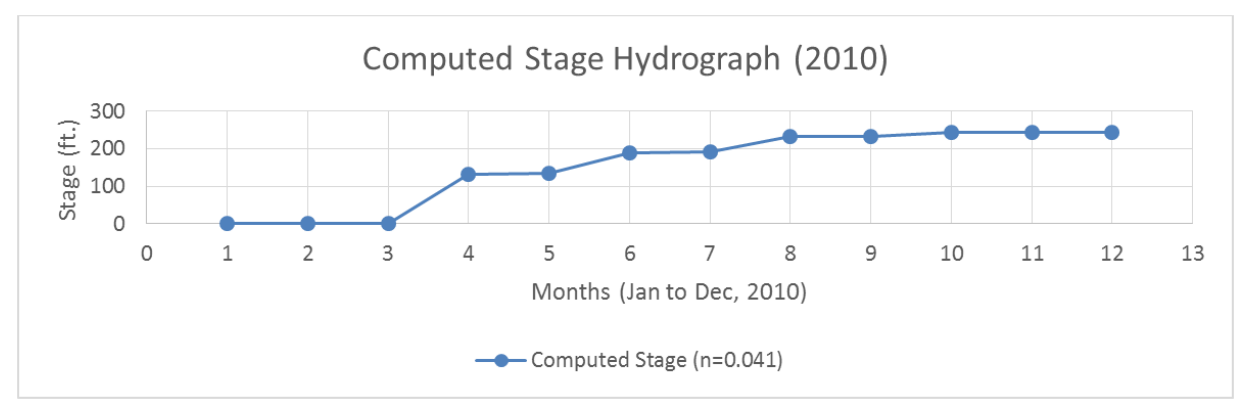

Figure 11. Computed Stage Hydrograph at Station-01 for $n=0.041$. 


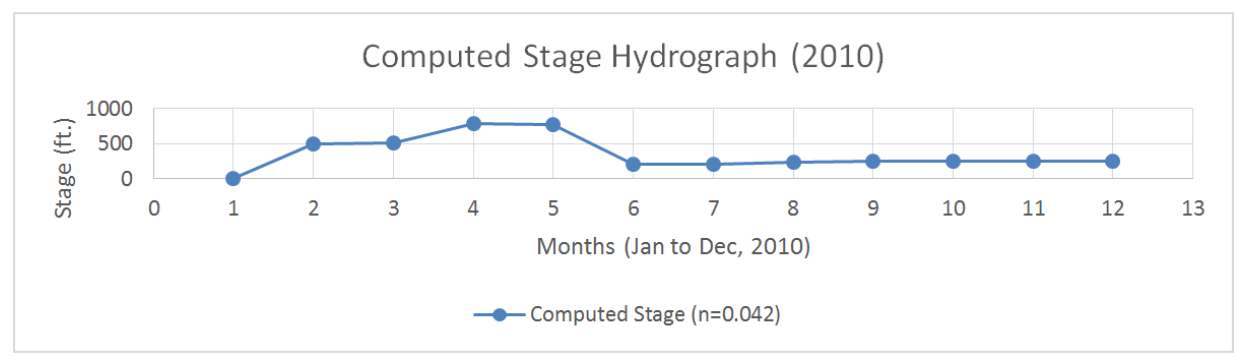

Figure 12. Computed Stage Hydrograph at Station no. 01 for $n=0.042$.

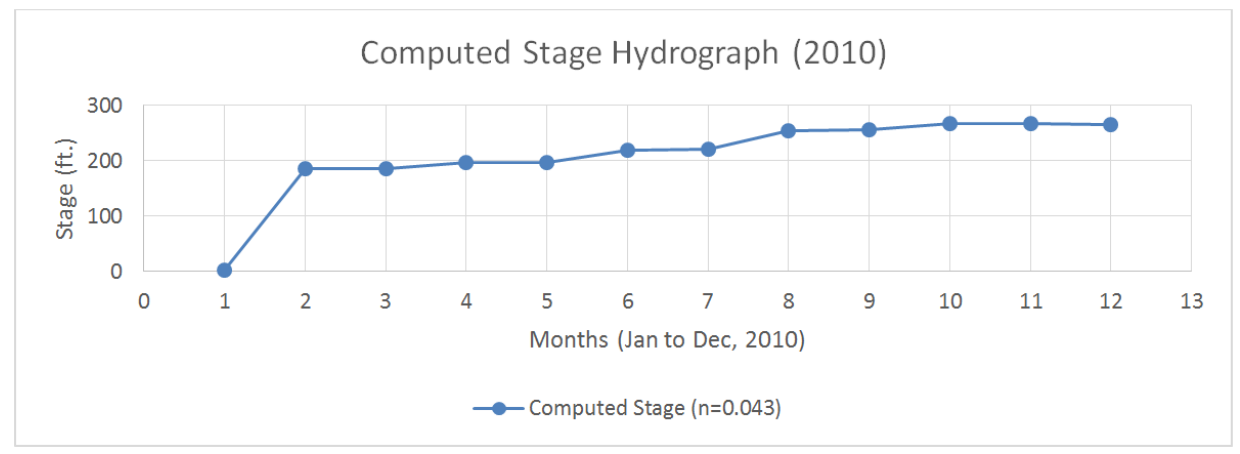

Figure 13. Computed Stage Hydrograph at Station no. 01 for $n=0.043$.

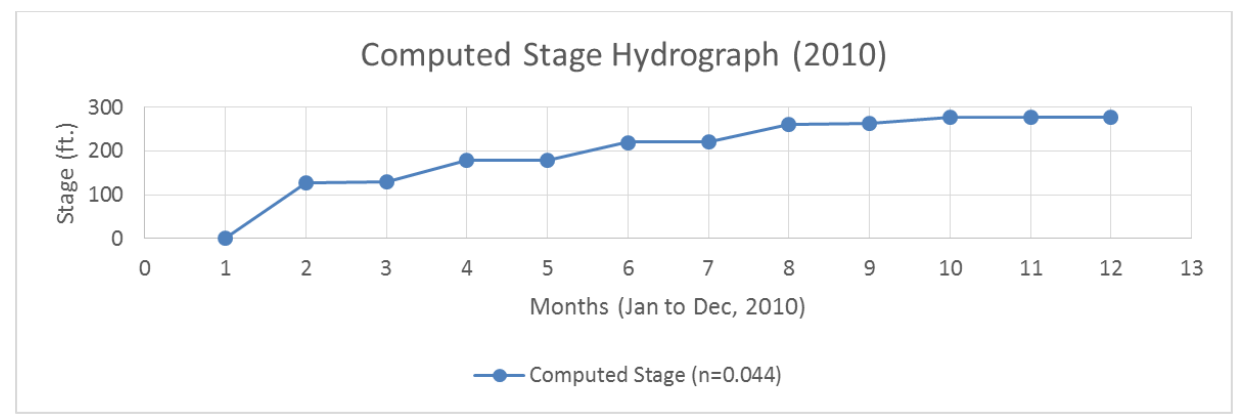

Figure 14. Computed Stage Hydrograph at Station no. 01 for $n=0.044$.

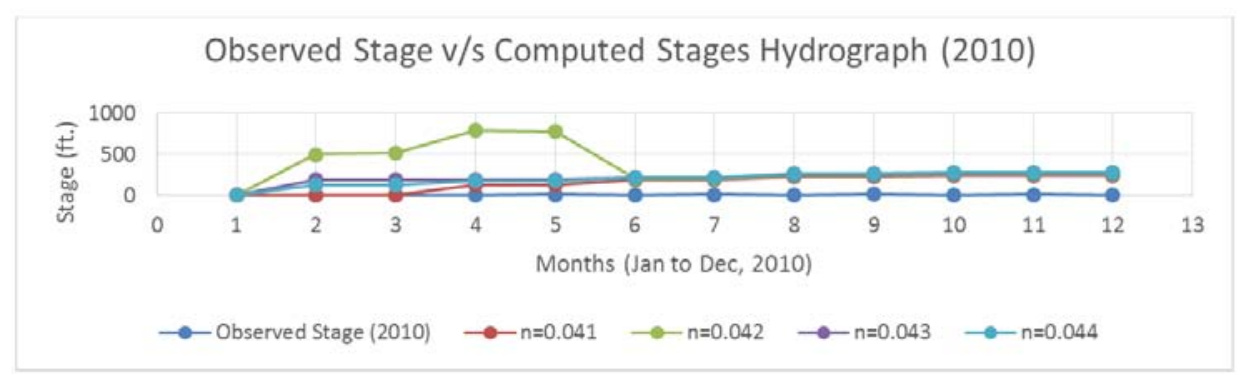

Figure 15. Observed v/s Computed Stages Hydrograph at Station no. 01.

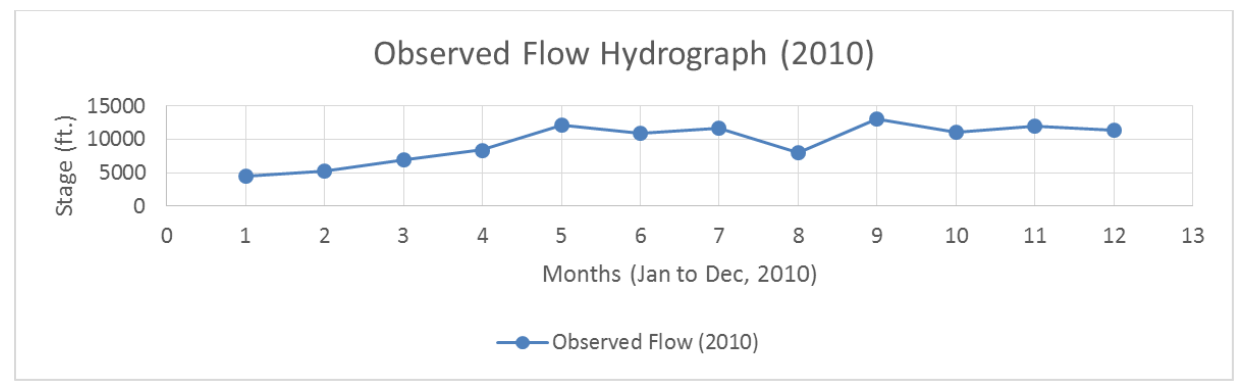

Figure 16. Observed Flow Hydrograph at Station no. 07. 


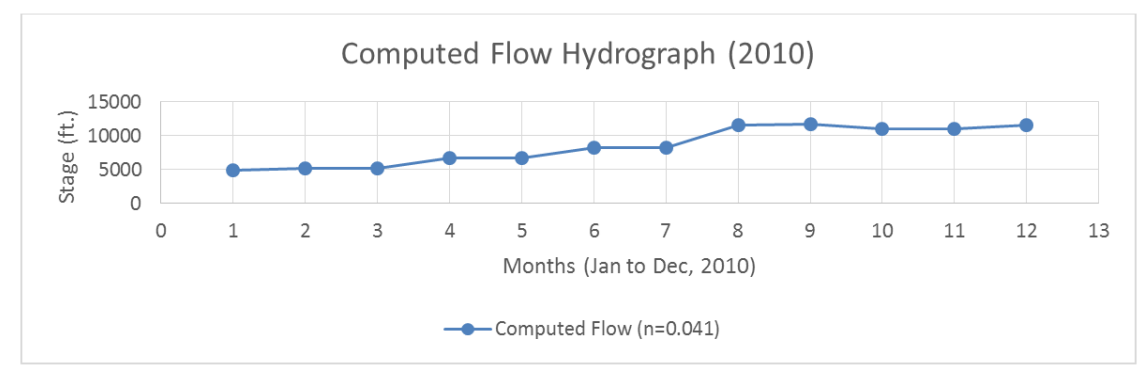

Figure 17. Computed Flow Hydrograph at Station no. 07 for $n=0.041$.

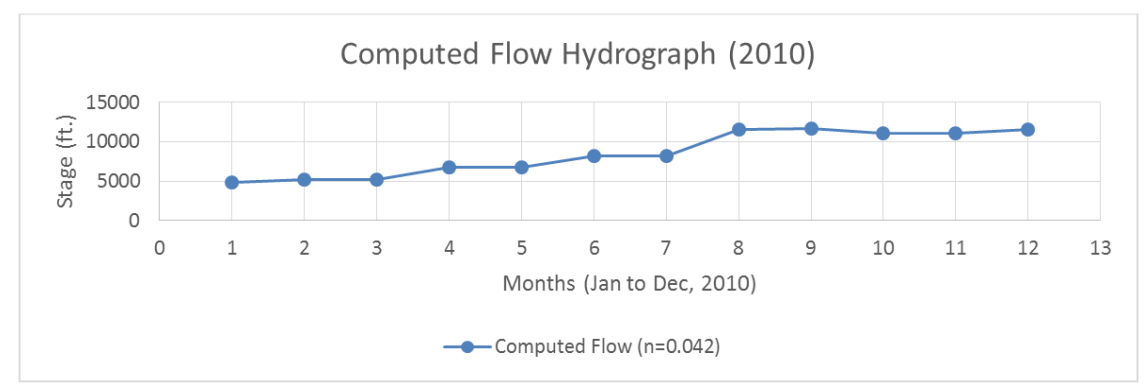

Figure 18. Computed Flow Hydrograph at Station no. 07 for $n=0.042$.

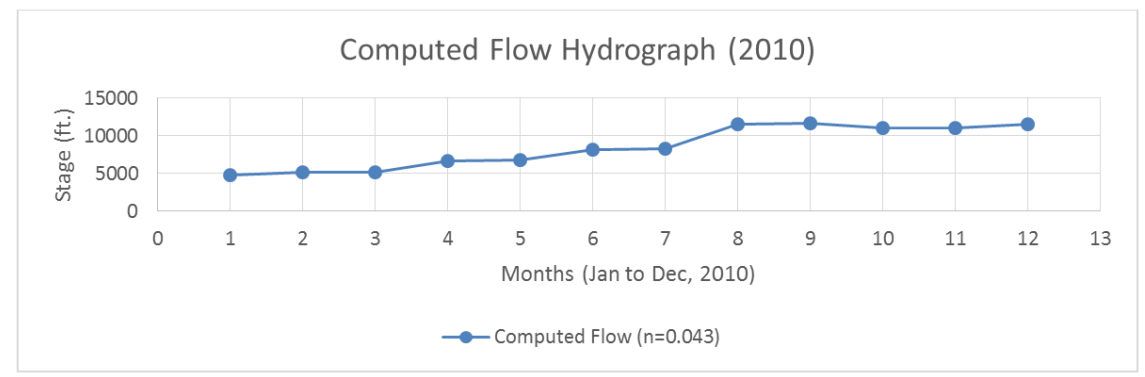

Figure 19. Computed Flow Hydrograph at Station no. 07 for $n=0.043$.

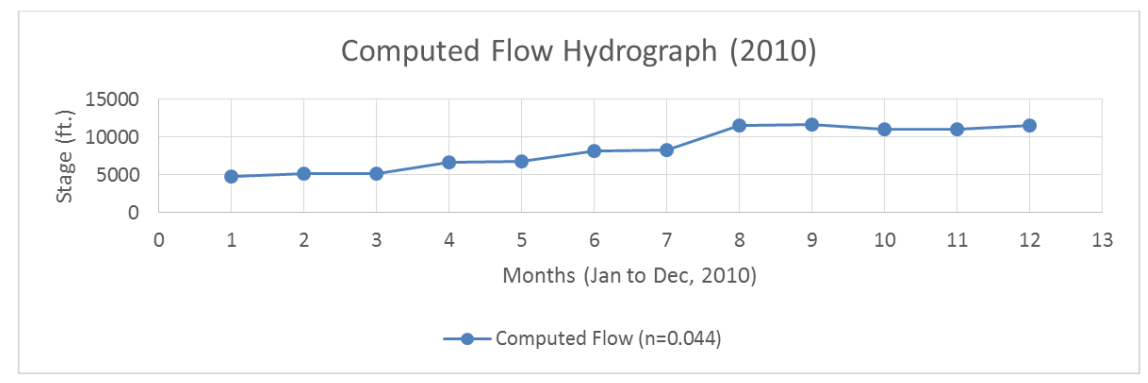

Figure 20. Computed Flow Hydrograph at Station no. 07 for $n=0.044$ 。

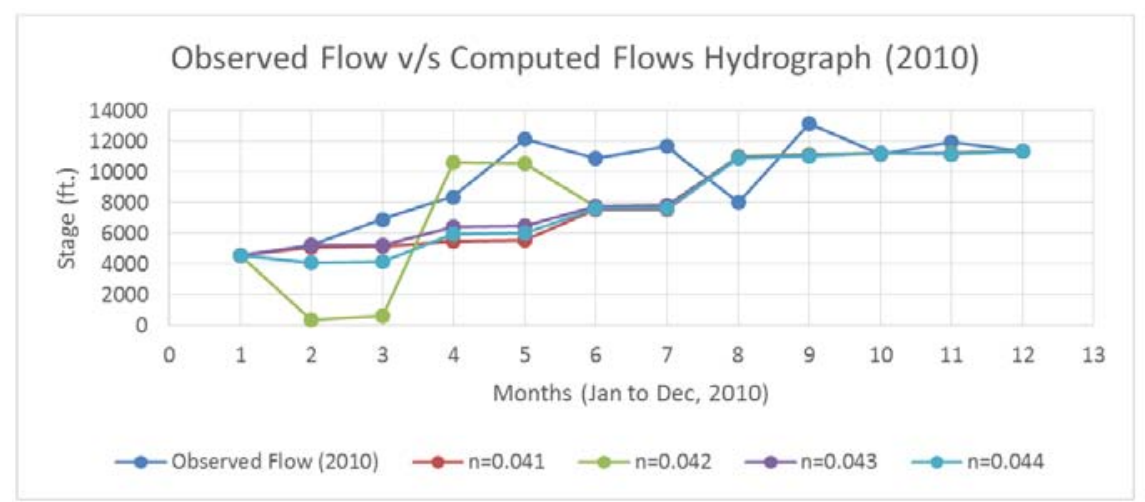

Figure 21. Observed Flow v/s Computed Flows Hydrograph at Station no: 07. 


\subsection{HEC-RAS Model Verification for the Rohri Canal}

The results of present research attained by using the values of $\Delta \mathrm{t}$ and $\theta$ according to Fread et al, 1998 showing that the value of roughness coefficient from 0.040 to 0.045 is giving a closer agreement of the observed and computer hydrographs. Meanwhile, after observing the observed and flow hydrographs for all the set of values ranging from 0.040 to 0.045 , it was concluded that the observed and flow hydrograph is showing a reliable and good agreement or we can say that they are coinciding on the value of 0.042 , as we can see in the (Figure 18; Figure 19).

However, sometimes the model made using the HEC-RAS software may go unstable when we start the simulation because of unsatisfactory values of initial conditions. Though, it is generally believed that the discharge measurements are subjected to so many uncertainties and may also contain errors.

\subsection{Root Mean Square Test}

The results shows that values obtained by comparing between the observed values and computed values of hydrographs; that of stage values at station- 1 and flow values at station-7. It is observed that the roughness coefficient value of 0.042 is giving the smallest root mean square value (Table 1).

Table 1. Statistical Analysis of Results.

\begin{tabular}{|c|c|c|c|c|c|}
\hline Station \# & $\Delta \mathrm{T}$ (Months) & $\boldsymbol{\theta}$ & $\mathbf{n}$ & 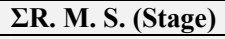 & 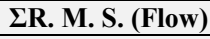 \\
\hline \multirow{4}{*}{1} & \multirow{4}{*}{1} & \multirow{4}{*}{0.95} & 0.041 & 10.664 & \multirow{4}{*}{$*$} \\
\hline & & & 0.042 & 10.664 & \\
\hline & & & 0.043 & 10.664 & \\
\hline & & & 0.044 & 10.664 & \\
\hline \multirow{4}{*}{7} & \multirow{4}{*}{1} & \multirow{4}{*}{0.95} & 0.041 & \multirow{4}{*}{$* *$} & 174.68 \\
\hline & & & 0.042 & & 8449.28 \\
\hline & & & 0.043 & & 8449.28 \\
\hline & & & 0.044 & & 8449.28 \\
\hline
\end{tabular}

Note: for this analysis, the flow values are used as the upstream boundary condition, and stage values are used as downstream boundary conditions.

As we know that, the model verification always remain an important test for all type of simulations, and so is achieved by doing that on the data from the period of January to December, 2011. For this analysis, assumed value of roughness coefficient is 0.042 , obtained from the calibration attempts. In order to do verification process on unsteady flow model, a comparison is made between the observed values and computed values of stage and flow hydrographs, and for that purposes, stage values considered are of station-1 and flow values are of station-7.
We have chosen these locations or points because of the reason that there were no daily measurements on other points of the Rohri Canal. So, we focused on those points, on which, there were daily measurements of stage and flow. After putting all the necessary information into the verification process, it was observed that the roughness coefficient value of 0.042 is showing reasonable closeness between the observed and computed values of stage and flow hydrographs (Figures 22; Figure 23).

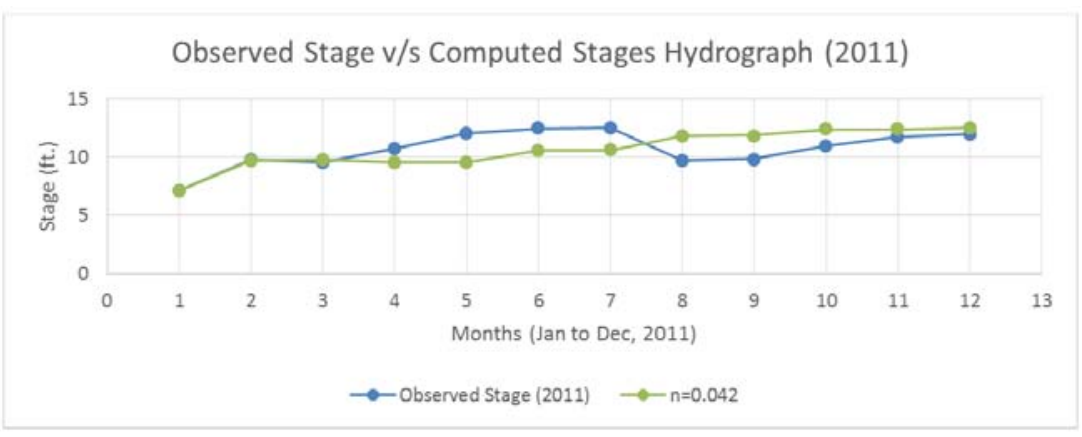

Figure 22. Observed and Computed Stage Hydrograph at Station no. 01 for the $n=0.042$.

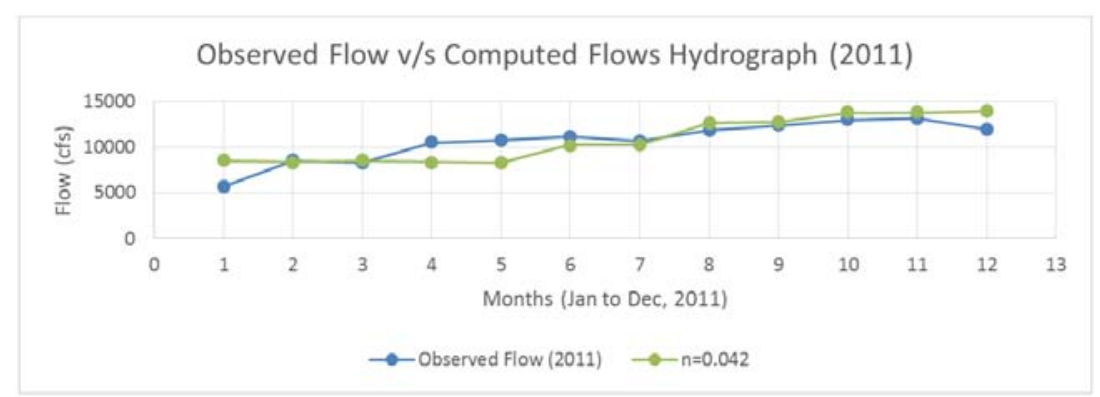

Figure 23. Observed and Computed Flow Hydrograph at Station no. 07 for the $n=0.042$. 


\section{Conclusion}

HEC-RAS model of unsteady flow is made for the upper reach of Rohri Canal. The most reliable value obtained from all the process of calibration and verification for the period of 2010 and 2011 respectively is found to be 0.042 . This value shows more or less perfect overlapping of the stage and flow hydrographs of the observed and computed values from the calibration and verification process.

\section{Conflicts of Interest}

All the authors do not have any possible conflicts of interest.

\section{Acknowledgements}

I would like to thank you the potential reviewer for their valuable comments and suggestions. I also thank my other colleague's valuable comments and suggestions that have helped to improve the manuscript.

\section{References}

[1] Ahmed, A., Iftikhar, H., \& Chaudhry, G. M. (2007). Water resources and conservation strategy of Pakistan. The Pakistan development review, 997-1009.

[2] B. Mishra and S. Behera, 7th International R\&D Conference on Development and Management of Water and Energy Resources, Bhubaneswar, 4-6 February 2009.

[3] Ding, Y. and Wang, S. Y. (2004), "Identification of Manning's Roughness Coefficient in Channel Network Using Adjoint Analysis", National Center for Computational Hydroscience and Engineering, University of Mississippi, USA.

[4] Doncker, L., Troch, P., Verhoeven, R., Bal, K., Meire, P., \& Quintelier, J. (2009). Determination of the Manning roughness coefficient influenced by vegetation in the river $\mathrm{Aa}$ and Biebrza river. Environmental fluid mechanics, 9 (5), 549-567.

[5] Fard, R. S., Heidarnejad, M., \& Zohrabi, N. (2013). Study factors influencing the hydraulic roughness coefficient of the Karun river (Iran). International Journal of Farming and Allied Sciences, 22 (2), 976-981.

[6] Gupta, B. L. (2007), "Water resources systems and Management", 2nd edition. ISBN: 81-8014-106-3, Standard Publishers, Delhi. www.engineering books.co. in.

[7] Government of Orissa, (2010) "Department of Water Resources, Mahanadi at a Glance, Vol. 1.

[8] Kahlown, M. A., \& Majeed, A. (2003). Water-resources situation in Pakistan: challenges and future strategies. Water Resources in the South: present scenario and future prospects, 20.
[9] Mayo, T., Butler, T., Dawson, C., \& Hoteit, I. (2014). Data assimilation within the Advanced Circulation (ADCIRC) modeling framework for the estimation of Manning's friction coefficient. Ocean Modelling, 76, 43-58.

[10] Olsen, N. R. B. (2002). Hydroinformatics, fluvial hydraulics and limnology. Norwegian University of Science and Technology. Trondheim, Noruega.

[11] Phillips, J. V., \& Tadayon, S. (2006). Selection of Manning's roughness coefficient for natural and constructed vegetated and non-vegetated channels, and vegetation maintenance plan guidelines for vegetated channels in Central Arizona: US Department of the Interior, US Geological Survey Washington, DC.

[12] Pruski, F. (2006). Hidros: dimensionamento de sistemas hidroagrícolas: Editora UFV.

[13] P. V. Timbadiya, P. L. Patel and P. D. Porey, (2011) "Calibration of HEC-RAS Model on Prediction of Flood for Lower Tapi River, India," Journal of Water Resources and Protection, Vol. 3, 2011, pp. 805-811.

[14] S. Patro, C. Chatterjee, S. Mohanty, R. Singh and N. S. Raghuwanshi, (2009) "Flood Inundation Modeling Using Mike Flood and Remote Sensing Data," Journal of the Indian Society of Remote Sensing, Vol. 37, No. 1, pp. 107.

[15] Teixeira, E. K. d. C., Coelho, M. M. L. P., Pinto, E. J. d. A., Diniz, J. G., \& Saliba, A. P. M. (2018). Manning's roughness coefficient for the Doce River. RBRH, 23.

[16] HEC (Hydrologic Engineering Center) (2009) "One dimensional - unsteady flow through a full network of open channels", User's manual, U.S. Army Corps of Engineers, Davis, CA. (http://www.hec.usace.army.mil/software/HECRAS/hecrasdownload.html).

[17] US Army Corps of Engineers, "HEC-RAS, User Manual, 2008”, Hydrologic Engineering Center, Davis Version 4.0.

[18] R. Vijay, A. Sargoankar and A. Gupta, (2007) "Hydrodynamic Simulation of River Yamuna for Riverbed Assessment: A Case Study of Delhi Region", Environmental Monitoring Assessment, Vol. 130, No. 1-3, pp. 381-387.

[19] N. Usul and T. Burak, (2006) "Flood Forecasting and Analysis within the Ulus Basin, Turkey, Using Geographic Information Systems", Natural Hazards, Vol. 39, No. 2.

[20] Othman, N. Y (2006), "Hydraulic Control of Shatt Al-Hilla within Hilla City", MSc Thesis, College of Engineering, University of Babylon, Iraq.

[21] Van Lanen, H. A., Tallaksen, L. M., \& Rees, G. (2007). Annex II. Droughts and climate change. Commission Staff Working Document Impact Assessment (SEC (2007) 993).

[22] W. M. Bao, X.-Q. Zhang and S. M. Qu, (2009) "Dynamic Correction of Roughness in the Hydrodynamic Model," Journal of Hydrodynamics, Vol. 21, No. 2, pp. 255-263.

[23] Zink, J. M., \& Jennings, G. D. (2014). Channel roughness in North Carolina mountain streams. JAWRA Journal of the American Water Resources Association, 50 (5), 1354-1358. 